\title{
EFEITOS DA IMPOSIÇÃO DE BARREIRAS TÉCNICAS E FITOSSANITÁRIAS NAS EXPORTAÇÕES BRASILEIRAS DE MAMÃO ${ }^{1}$
}

\author{
Rosane Nunes de Faria ${ }^{2}$ \\ Viviani Silva Lírio ${ }^{3}$ \\ Orlando Monteiro da Silva \\ João Eustáquio de Limas
}

\begin{abstract}
Resumo - O objetivo principal deste trabalho é identificar as medidas técnicas e fitossanitárias impostas pelos Estados Unidos, as quais podem se configurar barreiras, e quantificar o efeito dessas barreiras no volume exportado de mamão. A metodologia empregada consistiu em uma abordagem qualitativa, por meio de entrevistas, e em uma abordagem quantitativa, pela qual foi utilizado modelo de séries temporais. Foram identificadas cinco medidas que podem se considerar barreiras. Quantificou-se o impacto de duas dessas barreiras, porém apenas uma se mostrou significativa, o que indica efeitos da imposição de barreiras técnicas e fitossanitárias no volume exportado de mamão. Assim, pode-se dizer que os exportadores de mamão têm enfrentado a imposição de barreiras, e o governo brasileiro teria argumentos técnicos para discutir e tentar solucionar essas questões, bilateralmente, com os Estados Unidos, nos encontros regulares dos Comitês de Medidas Sanitárias e Fitossanitárias e de Barreiras Técnicas.
\end{abstract}

Palavras-chave: Barreiras técnicas e fitossanitárias, exportação, mamão-papaia.

\footnotetext{
Recebido em 28/02/2005

Aceito em 25/04/2005

2 Mestre em Economia Aplicada pela Universidade Federal de Viçosa. Endereço: Rua Trajano Reis, 186 B1 - 02/ 83 Jardim das Vertentes, São Pulo- SP 05541-030. telefone: (11) 3743-5710 e-mail: rnfaria@ esalq.usp.br

3 DS em Economia Rural pela UFV e profa Adjunta II do Departamento de Economia Rural UFV. Endereço: Departamento de Economia Rural s/n Campus Universitário, Viçosa - MG 36571-000. Telefone: (31) 38991330 e-mail: vslirio@ufv.br

4 Ph.D em Economia, North Carolina State UIniversity, EUA e prof. Titular do Departamento de Economia UFV. Endereço: Departamento de Economia s/n Campus Universitário, Viçosa - MG 36571-000. Telefone: (31) 3899-3204 e-mail: odasilva@ufv.br

5 Pós-Doctor, University of Flórida, EUA e prof. Titular do Departamento de Economia Rural UFV. Endereço: Departamento de Economia Rural s/n Campus Universitário, Viçosa - MG 36571-000. Telefone: (31) 38991332 e-mail: jelima@ufv.br
} 


\section{Introdução}

Após a Segunda Grande Guerra, as nações mais desenvolvidas voltaram sua atenção para a questão das negociações multilaterais. A partir de então, oito rodadas de negociações de comércio foram realizadas, visando, prioritariamente, a cortes de tarifas às importações. A Rodada Uruguai, uma das principais, resultou em um consenso sobre cortes, da ordem de 40\% nas tarifas médias dos países desenvolvidos (Krugman e Obstfeld, 2001).

De acordo com a Secretaria de Comércio Exterior - Secex (2003), paralelamente às reduções nas tarifas advindas dessas negociações, as Barreiras Não-Tarifárias - BNTs ganharam importância como mecanismo de proteção aos mercados nacionais. Para Weyerbrock e Xia (2000), as quedas nas barreiras tradicionais, como tarifas e cotas, têm levado os países a substituírem os mecanismos de proteção tradicionais por barreiras técnicas e fitossanitárias, que, mascaradas com o argumento de proteção à saúde do homem, dos animais e das plantas, são impostas com fins puramente comerciais.

Embora seja crescente a utilização de barreiras técnicas e fitossanitárias, há poucas informações a respeito de seus efeitos no comércio, na renda e no bem-estar mundial. Esse tipo de mecanismo de proteção é, geralmente, mais complexo e menos transparente que as tarifas, o que dificulta o seu estudo. Ademais, identificar uma barreira é tarefa árdua, pois uma norma ou um regulamento técnico não pode ser considerado barreira por si só; são consideradas barreiras quando são morosos e despendiosos, pouco transparentes e excessivamente rigorosos (Inmetro, 2003).

É importante considerar que alguns setores produtivos são mais diretamente afetados pelas exigências externas de cumprimento de padrões técnicos e medidas fitossanitárias, dentre eles, os de aves, suínos bovinos e frutas. De acordo com Ferraz Filho (1997), as exportações de frutas in natura enfrentam fortes barreiras em alguns mercados importantes, a exemplo do norte-americano, do japonês e de vários países 
Rosane Nunes de Faria, Viviani Silva Lírio, Orlando Monteiro da Silva \& João Eustáquio de Lima

da União Européia, justificadas pela presença de doenças nas áreas de produção ou de resíduos tóxicos nos produtos comercializados. Estudos realizados pela Embaixada do Brasil - Washington DC (2003) indicam que as restrições técnicas têm representado sérios entraves à expansão da fruticultura brasileira no mercado internacional.

Dentre as principais frutas tropicais exportadas pelo Brasil, cita-se a exportação de mamão-papaia, que está sujeita ao cumprimento de severas condições de cultivo, sanitização do campo de plantação, embalagem e transporte, dentre outros regulamentos que podem configurar barreiras.

As rigorosas exigências impostas aos exportadores de mamão-papaia podem indicar a utilização de barreiras técnicas e fitossanitárias como forma de mecanismo de proteção, tipo de restrição que prejudica o desempenho do setor exportador e afeta o volume do produto comercializado internacionalmente.

A partir dessa constatação, torna-se importante identificar as barreiras técnicas e fitossanitárias impostas às exportações de mamão e verificar os seus efeitos no fluxo de comércio, pois essas informações podem auxiliar o setor produtivo e o público a se guiarem, com maior clareza, nas negociações comerciais e nas discussões de normalização internacional. Ademais, no caso do Brasil, não foram encontrados estudos que buscassem quantificar esses efeitos nas exportações de frutas, especialmente nas exportações de mamão, o que evidencia a importância deste trabalho como fonte de informações úteis aos agentes interessados.

Este estudo objetivou identificar as barreiras técnicas e fitossanitárias impostas pelos Estados Unidos às exportações brasileiras de mamão, bem como quantificar os efeitos dessas barreiras no volume de mamão exportado para tal mercado. 


\section{Barreiras técnicas e fitossanitárias}

A inexistência de consenso quanto à definição de barreiras técnicas e fitossanitárias, juntamente com a dificuldade em distinguir uma medida de uma barreira, torna difícil a compreensão dos seus efeitos no bemestar e no comércio.

Cabe salientar, aqui, que as medidas técnicas e fitossanitárias não constituem barreiras per si; tal conotação se dá apenas quando as exigências nelas contidas vão além do aceitável. De acordo com o Inmetro (2003), uma barreira técnica pode surgir a partir de situações como ausência de transparência das normas ou dos regulamentos aplicados, imposição de procedimentos morosos ou despendiosos para avaliação de conformidade, ou em decorrência de regulamentos excessivamente rigorosos, impostos pelas legislações estrangeiras.

Castilho (1994) apresentou um resumo das situações em que medidas técnicas e fitossanitárias poderiam se caracterizar como barreira: a) imposição de padrões tecnológicos e culturais incompatíveis com o do país exportador, o que implica alterações importantes no processo produtivo, elevando custos sem justificativas técnicas; b) discriminação de produtos importados; c) discriminação de usos de insumos, especialmente em produtos agrícolas, sob a alegação não-comprovada de danos à saúde e ao meio ambiente; e d) falta de divulgação clara das exigências técnicas.

Com o objetivo de conter a proliferação dessas barreiras nos anos recentes, os países negociaram, durante a Rodada Uruguai em 1994, dois acordos sobre barreiras técnicas que disciplinam o uso de medidas fitossanitárias e técnicas: o Agreements on Sanitary and Phytosanitary Measures - SPS e o Technical Barriers to Trade Agreement - TBT.

Esses acordos objetivaram manter o direito de os países de adotarem normas, regulamentos e medidas técnicas e fitossanitárias que julgarem apropriados à proteção da saúde humana, dos animais e dos vegetais e, 
Rosane Nunes de Faria, Viviani Silva Lírio,

Orlando Monteiro da Silva \& João Eustáquio de Lima

ao mesmo tempo, assegurar que tais medidas não sejam impostas arbitrariamente, o que resultaria em desnecessárias barreiras ao comércio. Dessa forma, para garantir que medidas não se configurem barreiras, os países deveriam seguir o que está disposto nesses dois acordos.

A definição de barreiras adotada neste trabalho é de Castilho (1994), devendo levar em consideração que, além das situações apresentadas pela autora, será considerada também como barreira toda medida que venha ferir qualquer dispositivo dos acordos SPS e TBT.

\section{Metodologia}

A metodologia deste estudo consiste na utilização conjunta de uma abordagem qualitativa e uma quantitativa. O estudo de múltiplos casos é utilizado na abordagem qualitativa deste trabalho, pois, por meio de entrevistas, é possível identificar a imposição de barreiras às exportações de mamão. As barreiras identificadas nessa fase são utilizadas, posteriormente, no modelo econométrico de análise de intervenção, para que os seus efeitos no volume exportado desse produto possam ser quantificados.

Foram realizadas entrevistas em três empresas, sendo duas delas as maiores exportadoras do País. Também foram entrevistadas pessoaschave no Departamento de Defesa e Inspeção Vegetal - DDIV, do Ministério da Agricultura, Pecuária e Abastecimento - MAPA; na Divisão de Cooperação Técnica e Acordos Sanitários Internacionais - DCTA, do MAPA; na Delegacia Federal de Agricultura no Estado do Espírito Santo - DFA-ES; e no Instituto Capixaba de Pesquisa e Assistência Técnica e Extensão Rural - INCAPER.

Os dados secundários sobre as exportações de mamão para os Estados Unidos foram coletados no sistema ALICEWEB, no site do Ministério de Desenvolvimento Indústria e Comércio - MDIC. 
A abordagem quantitativa utiliza um modelo de série temporais, por meio do qual se buscam no próprio processo gerador da série em que se analisam as exportações de mamão, o entendimento de sua evolução. Segundo Gujarati (2001), a modelagem ARIMA procura explicar o comportamento de uma variável $y_{t}$ por meio de seus próprios valores passados e dos termos de erro estocásticos.

No entanto, a trajetória de uma série de tempo pode ser substancialmente alterada por eventos anormais dificilmente quantificáveis, como medidas tomadas por agentes econômicos ou eventos excepcionais. Tais eventos foram denominados intervenções, e a inclusão delas nos modelos ARIMA, por meio de variáveis dummy, dá origem aos modelos de análise de intervenção.

Tendo em vista que as medidas técnicas e fitossanitárias (eventos dificilmente quantificáveis) possam alterar, substancialmente, a série de exportação de mamão brasileiro, o modelo de intervenção é oportuno para quantificar os efeitos de tais medidas.

Seguindo a notação de Vandaele (1983), tem-se:

$$
E X P_{U S A_{t}}=\frac{\omega_{1}(B)}{\delta_{1}(B)} I_{1, t}+\ldots+\frac{\omega_{m}(B)}{\delta_{m}(B)} I_{m, t}+N_{t}
$$

em que

$E X P_{U S A t}=$ volume exportado em toneladas de mamão-papaia para os Estados Unidos;

$I_{l, t} \ldots I_{m} t=$ varáveis dummies que representam as barreiras técnicas e fitossanitárias, identificadas por meio do estudo de caso realizado; e $\frac{\omega(B)}{\delta(B)}=$ forma do impacto determinada pela avaliação que o pesquisador faz da intervenção, quanto a dois aspectos: início do impacto desta na série $y_{t}$ (imediato ou gradual) e a duração do impacto (temporário ou permanente);

$N_{t}=$ termo de erro representado por um ARIMA. 
Rosane Nunes de Faria, Viviani Silva Lírio,

Orlando Monteiro da Silva \& João Eustáquio de Lima

Embora o modelo tenha se mostrado adequado à análise, algumas limitações devem ser ressaltadas, como, por exemplo, a possibilidade de captação do efeito de outras intervenções que não sejam as almejadas. Além disso, como o comportamento da série em análise é explicado apenas por seus valores passados e por erros atuais e passados, não incluindo no modelo outras variáveis explicativas, o impacto de algumas destas também pode ser captado pelo modelo, como, por exemplo, o efeito de valorização e de desvalorização da taxa de câmbio.

\section{Resultados e discussão}

No caso do mamão, as restrições fitossanitárias impostas pelos Estados Unidos advêm, fundamentalmente, da preocupação de infestação de moscas-das-frutas em seu território. Em 1985, os Estados Unidos proibiram o tratamento quarentenário empregado no Brasil, sob a alegação de que a substância utilizada (dibrometo de etileno) era cancerígena. O Brasil permaneceu 13 anos sem exportar mamão para o mercado americano, até que, em 1998, foi aprovado o System Approach ${ }^{6}$, que permitiu a volta da comercialização do mamão para esse mercado. Com a aprovação desse sistema foi elaborado um programa de exportação de mamão brasileiro, por meio do qual foi estabelecido um Plano de Trabalho que delega competência e responsabilidades aos envolvidos, com vistas em prevenir a introdução de pragas no território americano. Neste Plano de Trabalho também estão explícitas as diretrizes para a aplicação do System Approach e que devem ser seguidas pelos exportadores.

Nesse Plano de Trabalho conta que, todo ano, as exigências serão revistas e modificadas, de acordo com as necessidades, porém o plano discutido em 1998 funciona até hoje. Segundo os entrevistados, o Brasil vem pedindo alterações essenciais nesse plano, porém elas ainda não foram atendidas, pois os americanos, mesmo com embasamento científico

\footnotetext{
O System Approach é a integração de práticas de pré e pós-coleita empregadas na produção, na colheita,, no empacotamento e no transporte dos frutos, que proporcionam,em cada passo, a garantia de que o produto está livre da praga em questão. Para maiores detalhes, ver Martins e Malavasi (2003).
} 
apresentado pelo País, são morosos na avaliação dos pedidos e não mudam facilmente a legislação. Uma questão complicada é como identificar se a demora em um processo de avaliação de conformidade para equivalência, assim como a demora nos processos de avaliação de Análise de Risco de Praga - ARP pelo Departamento de Agricultura dos Estados Unidos, pode, ou não, ser caracterizada como barreira ao comércio. No caso específico do mamão, segundo agentes entrevistados no INCAPER e no MAPA, toda essa demora na aprovação dos pedidos e nos processos de avaliação de ARP não é necessária, haja vista a experiência que o Brasil possui na realização desse tipo de análise. Dessa forma, essa demora é vista como uma barreira importante ao comércio de mamão, pois tem restringido as exportações do país.

\subsection{Possíveis barreiras ao comércio de mamão-papaia}

As principais modificações solicitadas até hoje e que podem se configurar barreiras técnicas e fitossanitárias são:

- Atualmente, o System Approach permite a exportação do mamão nos estágios de maturação 0, 1 e 2, como medida de segurança exigida pelos Estados Unidos. No entanto, os exportadores brasileiros solicitaram que esse estágio fosse expandido para 3, visando à maior flexibilidade na colheita e ao aumento das vendas, já que a fruta, em um estágio de maturação mais avançado, é mais saborosa. Esta solicitação foi feita no ano de 1999 e, até o momento, os Estados Unidos não se pronunciaram a respeito do pedido; alegam que a demora no processo de avaliação é um procedimento normal.

Entretanto, esse argumento é pouco confiável, pois uma Análise de Risco de praga mostrou que a mudança solicitada no programa System Approach não causaria impactos significativos na probabilidade, que é extremamente baixa, de introdução de moscas-das-frutas nos Estados Unidos. 


\section{Rosane Nunes de Faria, Viviani Silva Lírio, Orlando Monteiro da Silva \& João Eustáquio de Lima}

Assim, ficou comprovado, cientificamente, que a exportação de papaia no estágio 3 de maturação não aumentaria o risco de infestação da praga. No artigo 5, do Acordo SPS - Análise de risco e determinação do nível de proteção sanitária e fitossanitária apropriado, no Parágrafo $6^{\circ}$, é instituído que, quando medidas sanitárias e fitossanitárias são estabelecidas e mantidas para alcançar o nível de proteção sanitária e fitossanitária considerado apropriado, os Membros devem assegurar que tais medidas não sejam mais restritivas ao comércio do que o requerido para alcançar tal nivel de proteção.

À luz do Acordo SPS, a não-aceitação, pelo menos até o momento, do pedido de mudança do estágio de maturação indica a utilização de barreira fitossanitária. Essa afirmação está fundamentada no fato de que a exigência de exportação da papaia até o estágio 2 é mais restritiva ao comércio do que o requerido para alcançar o nível de proteção apropriado, pois outra medida, que é a exportação até o estágio 3 , é menos restritiva ao comércio e, ao mesmo tempo, garante o nível de proteção considerado adequado pelos Estados Unidos.

- Inicialmente, as frutas incluídas no programa de exportação para os Estados Unidos foram as remessas comerciais do grupo Solo de papaia: Sunrise, Kapoho, Sunset e Waimanalo. Quando o Brasil iniciou suas exportações, em setembro de 1998, foi pedida a introdução do cultivar Golden no programa de exportação. Para isso, foi realizada uma análise biomolecular para comprovar o grau de parentesco entre o cultivar Golden e as variedades já em franco processo de exportação para o mercado americano. Mediante essa análise, o Brasil comprovou, cientificamente, que as mesmas medidas aplicadas às outras variedades de mamão poderiam ser aplicadas à variedade Golden, mantendo-se o mesmo nível, considerado apropriado pelos Estados Unidos, de proteção fitossanitária. Entretanto, a exportação dessa variedade só foi liberada em agosto de 1999, quase um ano após o pedido ter sido feito. A burocracia nos processos de avaliação dos Estados Unidos e a demora nas mudanças na legislação restringem, desnecessariamente, o comércio e têm sido consideradas barreiras importantes pelos exportadores brasileiros. 
Essa restrição, que, por um ano, foi imposta à exportação do cultivar Golden, pode ser considerada barreira fitossanitária, pois condiz com o que está instituído no Parágrafo $6^{\circ}$, do Artigo 5, do Acordo SPS. O Brasil comprovou, cientificamente, que a exportação do cultivar Golden não teria impacto significativo na probabilidade de infestação de moscasdas-frutas nos Estados Unidos. Assim, em vez de proibir a importação dessa variedade, o que restringe totalmente o comércio, os Estados Unidos poderiam ter considerado válidas as medidas fitossanitárias empregadas no Brasil, que são menos restritivas e garantem o nível de proteção considerado adequado àquele país.

Pode-se considerar, então, que a aceitação da importação da variedade Golden pelos Estados Unidos foi, de fato, a retirada de uma barreira fitossanitária às exportações brasileiras de mamão. Em agosto de 1999, ocorreu o primeiro embarque de mamão Golden para os Estados Unidos e, desde então, essa variedade passou a ser exportada continuamente.

- Segundo as entrevistas realizadas nas empresas e nos órgãos públicos, um sério problema relativo ao mamão são as cargas da fruta rechaçadas pelos americanos, por encontrarem larvas de lepdópetros, sem a identificação ao menos em nível de gênero e sem qualquer indício de que aquele inseto possa ser uma praga quarentenária para o país. Do ponto de vista técnico, a devolução das cargas de mamão deveria estar baseada, no mínimo, em uma indicação de que aquele organismo pudesse constituir praga quarentenária.

Um dos pilares fundamentais do Acordo SPS são as justificativas científicas para adoção de medidas pelos Membros. No Parágrafo $2^{\circ}$, do Artigo $2^{\circ}$ do SPS, é estabelecido que os membros devem assegurar que qualquer medida sanitária ou fitossantária seja aplicada somente na extensão necessária para a proteção da vida e da saúde dos homens, animais e plantas e que estas medidas estejam baseadas em princípios científicos e não sejam mantidas sem evidência científica suficiente. 
Rosane Nunes de Faria, Viviani Silva Lírio, Orlando Monteiro da Silva \& João Eustáquio de Lima

Contrariando essa diretriz do Acordo, pode-se concluir que as devoluções de cargas de mamão constituem barreiras fitossanitárias às exportações brasileiras, pois os Estados Unidos agem, arbitrariamente, ao embargarem cargas da fruta sem evidência científica suficiente.

- A norma publicada pelos Estados Unidos, em 1998, permitiu apenas a exportação de papaia produzido no norte do Espírito Santo. No entanto, os exportadores brasileiros consideraram atrativo produzir a fruta no Nordeste do Brasil, especificamente nos estados da Bahia e do Rio Grande do Norte, devido, principalmente, à questão de logística de transporte. Com o objetivo de ampliar a área de exportação de papaia do Brasil foi feita uma ARP, pela qual foi comprovado que a probabilidade de introdução de moscas-das-frutas, provenientes do mamão produzido nessas áreas, é infinitamente baixa. Essa análise foi submetida ao Departamento NorteAmericano de Agricultura em maio de 2003 e, até o momento, o Brasil não obteve resposta.

Analogamente à análise realizada para o pedido de mudança no estágio de maturação da fruta, a demora no reconhecimento do pedido de expansão das áreas de exportação pode ser considerada uma barreira, pois está em desacordo com o Parágrafo $6^{\circ}$, do Artigo $5^{\circ}$ do SPS. Seguindo as diretrizes desse acordo, embora a proibição da importação dessas áreas seja uma forma de reduzir o risco de entrada de moscas-dasfrutas, os Estados Unidos deveriam aceitar a aplicação das medidas estabelecidas no System Approach nessas áreas, pois foi comprovado, cientificamente, que estas asseguram um nível de proteção considerado adequado a esse país, e são menos restritivas ao comércio.

É consenso, tanto entre empresas quanto entre órgãos públicos entrevistados, que a demora na liberação das áreas da Bahia e do Rio Grande do Norte é puramente comercial, pois, tecnicamente, está tudo comprovado. Segundo um entrevistado, no caso da liberação da Bahia, chegou a veicular, em outubro de 2003, uma informação de que essa área estivesse liberada. Entretanto, no mesmo dia da reunião que determinou a liberação desta área, houve uma negociação comercial 
entre Brasil e Estados Unidos, na qual o Brasil impôs algumas exigências para com a importação do trigo americano. Desse modo, os Estados Unidos recuaram na negociação da Bahia, para aguardar a decisão do Brasil na questão do trigo.

Para um respondente do Ministério da Agricultura, na verdade, não há justificativas técnicas para tamanha demora na aprovação dessas áreas; o que ocorre, frequientemente, é que esses pedidos de alteração no Plano de Trabalho são utilizados como moeda de barganha no comércio internacional. As autoridades americanas recorrem ao argumento de preocupação com a saúde do homem, do animal e das plantas, para encobrir a verdadeira função da exigência imposta por eles, que é sua utilização como forma de negociação, o que a caracteriza como barreiras fitossanitárias.

- Após o atentado de 11 de setembro de 2001, o temor de ataques biológicos foi exacerbado no mundo, em especial nos Estados Unidos. Este país implementou, então, a Lei do Bioterrorismo (Public Health Security and Bioterrorism Preparedness and Response Act of 2002), cujo objetivo principal é a identificação de todos os participantes que integram a cadeia de abastecimento alimentar daquele país.

A Lei do Bioterrorismo afeta todas as empresas nacionais e estrangeiras que fornecem alimentos ao mercado norte-americano, devendo ser ressaltado que as seções que mais causam impactos às exportações brasileiras são as que estabelecem os seguintes procedimentos: registros de empresas (nacionais e estrangeiras), notificação prévia de chegada de carregamentos, rotulagem e detenção administrativa de produtos considerados ilegais (MDIC, 2004).

Segundo Zolotar (2003), no Subtítulo A, Seção 303, da referida Lei são propostas ações relacionadas com detenção administrativa e retenção temporária em portos de entrada de alimentos que, durante inspeção, exame ou investigação por oficial qualificado, demonstre "evidência digna de crédito" (credible evidence) ou informação que indique que o referido produto representa ameaça séria à saúde ou de morte a seres humanos e animais. 


\section{Rosane Nunes de Faria, Viviani Silva Lírio, Orlando Monteiro da Silva \& João Eustáquio de Lima}

Para a autora, a adoção do critério de "existência de evidência, razoavelmente digna de crédito", de que os alimentos em questão representam ameaça séria à saúde ou de morte a seres humanos e animais "estaria ferindo o disposto no Artigo 2.2; do Acordo TBT, no que concerne à necessidade de utilizar informações técnicas e científicas para avaliação da proporcionalidade ao risco quando da elaboração de um regulamento técnico. Este Artigo deixa clara a necessidade de informações técnicas e científicas".

Assim, as disposições contidas no Bioterrorism Act podem resultar em barreiras técnicas às exportações de mamão, já que fere o disposto no Artigo 2.2; do Acordo TBT.

A Lei entrou em vigor em dezembro de 2003 e, embora tenha sido implementada totalmente apenas em junho de 2004, os efeitos das novas exigências nas exportações e nos custos administrativos das empresas já foram sentidos. Para uma empresa respondente, o maior problema em relação à lei é o tempo gasto na organização do elevado número de documentos exigidos para o aviso prévio de chegada da carga nos Estados Unidos, o que eleva os custos administrativos da empresa.

Os resultados desta seção evidenciaram que, enquanto algumas medidas técnicas e fitossantiárias impostas à exportação de mamão são mais restritivas ao comércio do que o necessário para garantir a proteção ao homem, aos animais e às plantas, outras são utilizadas como moeda de barganha no comércio internacional. Isto indica que algumas restrições não são legítimas, ou seja, não são requeridas por razões de saúde, mas como forma efetiva de protecionismo.

Se essas medidas são utilizadas como forma de proteção ao mercado interno, quais são, em termos quantitativos, os efeitos dessas barreiras no volume exportado de mamão? Algumas barreiras identificadas nesta seção foram utilizadas como variáveis dummies na seção subseqüente, na qual se procurou responder a esta questão. 


\subsection{Efeitos das barreiras no volume exportado de mamão}

A abordagem qualitativa permitiu, por meio de entrevistas, a identificação de cinco barreiras impostas pelos Estados Unidos. A princípio, todas seriam empregadas como variáveis dummies no modelo de intervenção. No entanto, para utilizar essa modelagem é preciso o conhecimento detalhado dos momentos das intervenções ou choques, ou seja, é necessário o conhecimento da data exata em que foram impostas as barreiras e a forma como elas afetaram o volume exportado. A inexistência dessas informações essenciais impediu que se analisassem todas as restrições identificadas, portanto, foram mensurados os efeitos de apenas duas barreiras técnicas e fitossanitárias:

1) A liberação da exportação da variedade Golden para os Estados Unidos, em agosto de 1999, nomeada de Intervenção agosto/1999 - INT 08/ 1999. Com este evento, buscou-se quantificar o efeito positivo da retirada de uma barreira fitossanitária.

2) Entrada em vigor da Lei do Bioterrorismo, imposta pelos Estados Unidos em dezembro de 2003, chamada de Intervenção dezembro/2003 - INT 12/2003.

Essas duas barreiras foram, então, as variáveis dummies introduzidas nos modelos. A variável quantitativa utilizada foi o volume exportado de mamão, em toneladas, para os Estados Unidos - EXP ${ }_{\text {USA. }}$ Os dados têm periodicidade mensal e cobrem o período de setembro de 1998 a junho de 2004.

Para estimação dos modelos foram feitos testes de estacionariedade dos dados, por meio do teste de Dickey-Fuller aumentado (ADF), e trabalhouse com a série de exportação para os Estados Unidos na primeira diferença, já que a série é não-estacionária.

Após o diagnóstico, realizado por meio da análise de resíduo, da significância dos parâmetros e dos critérios Akaike Information Criterion 
- AIC e Swartz Bayesian Criterion - SBC, verificou-se que o ARIMA que melhor se ajustou aos dados da série de $E X P_{U S A}$, no período analisado, apresentou um parâmetro de média móvel de ordem 1 e um parâmetro de média móvel de ordem 2, além de necessitar de uma diferença de ordem 1, ou seja, um ARIMA $(0,1,2)$. As estimativas dos parâmetros desse modelo estão apresentadas na Tabela 1, e o modelo pode ser escrito matematicamente como segue:

em que

$$
\theta(B)=\left(1-0,459 B-0,362 B^{2}\right)
$$

\begin{tabular}{|c|c|c|c|c|}
\hline$S A=\overline{\left(\operatorname{Mode}_{\overline{0}} B\right)} a_{t}$ & Série & Parâmetro & Estimativa & Teste $\mathbf{t}$ \\
\hline MA (2) & $\mathrm{EXP}_{\text {USA }}$ & $\theta_{1}$ & $-0,459998$ & $-3,398584^{1}$ \\
\hline & & $\theta_{2}$ & $-0,362529$ & $-2,631167^{2}$ \\
\hline
\end{tabular}

1 - Significativo a $1 \%$

2 - Significativo a $5 \%$

Fonte: Dados da pesquisa.

Determinado o ARIMA apropriado, foi estimado o modelo com as intervenções para quantificar o efeito dessas duas barreiras às exportações. A categoria escolhida para representar tanto a liberação da importação do Golden - INT 08/1999, quanto a entrada em vigor da Lei do Bioterrorismo - INT 12/2003, foi uma intervenção cujo impacto é imediato e a duração permanente; sua representação matemática se encontra em Vandaele (1983). Definidas as categorias das intervenções, foi estimado o modelo completo, equação (3); e as estimativas dos parâmetros estão apresentadas na Tabela 2. 
em que

$$
\begin{aligned}
& \theta(B)=\left(1-0,459 B-0,362 B^{2}\right) ; \\
& \omega_{1}=\text { INT } 08 / 1999 ; \\
& \omega_{2}=\text { INT } 12 / 2003 ; \\
& I_{1 t}=\left\{\begin{array}{l}
0: \text { para os meses anteriores a agosto } \\
1: \text { para os meses subseqüentes; }
\end{array}\right. \\
& I_{2 t}=\left\{\begin{array}{l}
0: \text { para os meses anteriores a dezemt } \\
1: \text { para os outros meses subseqüentes }
\end{array}\right.
\end{aligned}
$$$$
E X P_{U S A}
$$ 
Rosane Nunes de Faria, Viviani Silva Lírio, Orlando Monteiro da Silva \& João Eustáquio de Lima

Tabela 2 - Estimativas dos parâmetros do modelo com a intervenção EXP $_{\text {USA }}$

\begin{tabular}{cccc} 
Modelo & Série & Parâmetro & Coeficier \\
\hline Completo & EXP $_{\text {USA }}$ & $\theta_{l}$ & $-0,50646$ \\
& & $\theta_{2}$ & $-0,30934$ \\
& INT 08/1999 & $\omega_{1}$ & 213,223 \\
& INT 12/2003 & $\omega_{2}$ & $-72,0401$ \\
\hline
\end{tabular}

${ }^{1}$ Significativo a $1 \%$.
${ }^{2}$ Significativo a $5 \%$.
${ }^{3}$ Não-significativo.
Fonte: Dados da pesquisa.

Conforme Tabela 2, a intervenção agosto de 1999, que representa a liberação da importação da variedade Golden pelos Estados Unidos, apresentou efeito significativo e positivo no volume exportado. Este resultado indica que a retirada da barreira fitossanitária elevou, imediatamente, o volume exportado de mamão em 213,22 toneladas por mês.

Para se ter idéia da magnitude do efeito da retirada dessa barreira, considere as exportações de junho de 2004, que totalizaram 609,5 toneladas. Assim, em relação a esse mês, a elevação das vendas com a retirada da barreira (213,22 toneladas por mês) representou $34 \%$ do valor total das exportações. Fica claro, então, que a retirada dessa barreira teve impacto positivo considerável no volume exportado.

Deve ser salientado que, em agosto de 1999, a taxa de câmbio sofreu pequena desvalorização, o que pode superestimar o resultado, tendo em vista que o modelo pode ter captado esse efeito também.

Quanto à Lei do Bioterrorismo, embora o coeficiente não tenha sido significativo, o sinal negativo indica que ela pode ter causado efeito restritivo no volume exportado. Como foi mencionado com base na 
entrevista, embora a Lei tenha sido implementada totalmente apenas em junho de 2004, uma empresa admitiu que já ocorreram perdas de clientes devido à burocracia na alfândega para liberação do produto, o que atrasa a entrega dos pedidos.

No entanto, é importante também ressaltar que outros eventos, que não a entrada em vigor da Lei, poderiam ser responsáveis pelo sinal negativo, ou seja, pela possível redução no volume exportado. Segundo uma empresa, em dezembro de 2003 houve excesso de fruta no mercado, especialmente a manga, o que acarretou significativa queda no preço desta fruta. Como a manga é uma fruta que compete com o mamão no mercado internacional, isso poderia ter causado redução no volume exportado de mamão, o que também poderia ter sido capturado pelo modelo.

Enfim, apesar da inexistência de informações essenciais sobre a quantificação dos impactos de todas as cinco barreiras identificadas por meio das entrevistas, os resultados mostraram que pelo menos uma das duas analisadas teve efeito significativo no volume exportado, o que revela a possibilidade de outras barreiras terem influenciado também o volume exportado. Um exemplo pode ser a demora na liberação das exportações de mamão para os Estados Unidos, provenientes dos Estados da Bahia e do Rio Grande do Norte. Como os exportadores já estão adequados às exigências do mercado americano, a liberação dessas áreas, que pode ser considerada como a retirada de uma barreira fitossanitária, provavelmente terá impacto positivo no volume exportado.

\section{Conclusões}

A não-observância de vários artigos do Acordo SPS e TBT tem levado à imposição de medidas técnicas e fitossanitárias que podem se configurar barreiras. Dessa forma, foram identificadas cinco barreiras impostas pelos Estados Unidos. 
Rosane Nunes de Faria, Viviani Silva Lírio,

Orlando Monteiro da Silva \& João Eustáquio de Lima

Observou-se que algumas medidas são mais restritivas ao comércio do que o necessário para alcançar um nível de proteção sanitária e fitossanitária considerado apropriado pelo país importador, enquanto outras são empregadas como moeda de barganha no comércio internacional. Isto indica que algumas restrições não são legítimas, ou seja, não são requeridas por razões de saúde, mas como forma efetiva de protecionismo.

Quanto aos efeitos dessas barreiras no volume exportado de mamão, apenas o desmantelamento da barreira imposta à variedade Golden apresentou-se positiva e significativa, o que indica que essa barreira estaria prejudicando o volume exportado.

Pode-se dizer, então, que os exportadores brasileiros de mamão têm se deparado, efetivamente, com barreiras técnicas e fitossanitárias impostas às suas exportações. Os resultados levam a concluir que o governo brasileiro teria argumentos técnicos para discutir e tentar solucionar essas questões bilateralmente com os Estados Unidos, nos encontros regulares dos Comitês de Medidas Sanitárias e Fitossanitárias e de Barreiras Técnicas.

Acredita-se que a imposição de barreiras técnicas e fitossanitárias tende a crescer nos próximos anos, pois o argumento de proteção à saúde e à vida dos homens e dos animais facilita sua utilização. Entretanto, a expectativa é de crescimento das exportações, desde que não cessem os investimentos nos campos de produção, nos packing houses e em pesquisas, ou seja, as exportações de mamão continuarão aumentando desde que os exportadores consigam superar as exigências.

O aumento da participação do setor frutícola na pauta de exportação do Brasil também pode levar o governo brasileiro a despender mais recursos (financeiros e humanos) em negociações internacionais, buscando conter a proliferação dessas barreiras.

Finalmente, acredita-se que o somatório dos esforços das empresas exportadoras (no sentido de adequar a produção às exigências externas) 
e do setor público (no sentido de negociar e evitar que as exigências se tornem barreiras) permitirá ao Brasil manter-se entre os maiores exportadores de mamão-papaia.

Sugestão para futuros trabalhos seria estender este estudo a outras culturas, especialmente às frutas in natura, cujas exportações são fortemente prejudicadas por barreiras técnicas e fitossanitárias, tendo em vista que o levantamento dessas informações poderia servir de subsídios tanto para o setor privado quanto para o setor público, no momento das negociações internacionais.

\section{Referências}

CASTILHO, M. R. Barreiras Não-tarifárias: o caso da imposição de restrições ambientais sobre as exportações brasileiras de papel e celulose. 1994. 106 p. Dissertação (Mestrado) - Universidade Federal do Rio de Janeiro, Rio de Janeiro, 1994.

EMBAIXADA DO BRASIL, WASHINGTON, DC. Barreiras a produtos e restrições a serviços e investimentos nos Estados Unidos. 3 ed. São Paulo: Aduaneiras, 2003. 143 p.

FERRAZ FILHO, G. Barreiras técnicas ao comércio internacional: a experiência das exportações barasileiras. Revista Brasileira de Comércio Exterior, n. 52, p. 47-56, julh./set. 1997.

GUJARATI, D. N. Econometria Básica, 3 ed. São Paulo: Makron Books, 2001. 846 p.

INMETRO - Instituto Nacional de Metrologia, Normalização e Qualidade Industrial. Barreiras Técnicas: Conceitos Básicos. Acesso em: 13 nov. 2003. Disponível em: <http:/www.inmetro.gov.br/barreirastecnicas/ asbtc.asp>. 
Rosane Nunes de Faria, Viviani Silva Lírio,

Orlando Monteiro da Silva \& João Eustáquio de Lima

KRUGMAN, Paul. R e OBSTFELD, Maurice. Economia internacional: teoria e política, 5 ed. São paulo: Makron Books, 2001. 797 p.

MARTINS, D. S; MALAVASI, A.. "System Approach" na produção de mamão no Espírito Santo, como garantia de segurança quarentenária contra moscas-das-frutas. In: A cultura do mamoeiro. Vitória: INCAPER, 2003.

MDIC - Ministério do Desenvolvimento Indústria e comércio. Organização Mundial do Comércio - OMC. Acesso em: 21 julh. 2004. Disponível em:http://www.desenvolvimento.gov.br/sitio/secex/ negInternacionais/omc/gatt.php>.

SECEX - Secretaria de Comércio Exterior. Barreiras externas às exportações brasileiras para Estados Unidos, Japão e União Européia. Acesso em: 09 nov. 2003. Disponível em: <http:// www.cni.org.br/produtos/com_ext/barreiras2001.htm>.

VANDAELE, W. Applied time series and Box-Jenkins models. New York: Academic Press, 1983. 417 p.

WEYERBROCK, S.; XIA, T. Technical trade barriers in US/Europe agricultural trade. Agribusiness, v.16, n.2, p. 235-251, 2000

ZOLOTAR, M. S. Comentários sobre o Bioterrorism Act à luz do acordo sobre barreiras técnicas ao comércio da OMC. Acesso em: 05 nov. 2003. Disponível em: <http:/www.inmetro.gov.br/ barreirastecnicas>. 


\begin{abstract}
The main objective of this paper was to identify technical and sanitary requirements that could be qualified as export barriers for the Brazilian papaya and to quantify their effects on the volume exported to the United States of America. The methodology consisted of both qualitative and quantitative analysis. Qualitative information collected by means of interviews with producers and exporters were analyzed with the use of frequencies and descriptive statistics. A time series model of transfer function was estimated to analyze the impact of technical and sanitary barriers upon Brazilian papaya exports. Through the qualitative analysis it was possible to identify five technical and sanitary requirements that could be qualified as export barriers. Due to the lack of appropriate time series data, only two of them were subject to quantitative investigation. It was concluded that the Brazilian papaya exports have been negatively affected by these barriers and that this could be discussed bilaterally with the United States in the regular meetings of the Technical and Sanitary Barriers Committee.
\end{abstract}

Keywords: Technical barriers, sanitary requirements, papaya, transfer function model. 